\title{
Educar para a emancipação humana: o papel atual da escola e a busca por políticas LGBT ${ }^{1}$ no ambiente escolar
}

\author{
Francisco Brenno Soares Cavalcante ${ }^{2}$ \\ Maria Madalena da Silva ${ }^{3}$
}

\begin{abstract}
Resumo: O presente trabalho aborda como a escola passa a ser uma ferramenta indispensável para a manutenção da opressão LGBT dentro da sociedade centrada no conflito de classes. Além disso, identifica os entraves e propõe medidas de enfrentamento a invisibilidade que o público LGBT está submetido no ambiente escolar, assim, busca um vislumbramento de uma educação compromissada com a construção de uma sociedade emancipada no combate a toda e qualquer opressão.
\end{abstract}

Palavras-chave: Diversidade Sexual na Escola; Homofobia na Escola; Educação; Políticas LGBT.

\begin{abstract}
This paper discusses how the school becomes an indispensable tool for the maintenance of LGBT oppression within society focused on class conflict. It identifies barriers and proposes measures to tackle the invisibility that the LGBT audience is subjected in the school environment thusseeks a glimpse of an education committed to building a society emancipated in combating any and all oppression.
\end{abstract}

Keywords: Sexual Diversity in Schools; Homophobia in Schools; education; LGBT policies.

Resumén: En este trabajo se analiza cómo la escuela se convierte en una herramienta indispensable para el mantenimiento de la opresión LGBT dentro de la sociedad centrada en el conflicto de clases. Identifica las barreras y propone medidas para hacer frente a la invisibilidad que el público LGBT se somete en el ambiente escolar por lo tanto se busca una visión de una educación comprometida con la construcción de una sociedad emancipada en la lucha contra cualquier y toda opresión.

Palabras-clave: Diversidad sexual en las escuelas; Homofobia en las escuelas; Educación; Políticas LGBT.

\section{Introdução}

$\mathrm{Na}$ atual sociedade centrada no conflito de classes, a escola passa a assumir um papel fundamental para legitimar sua hegemonia tanto na esfera política (adotando a imposição de padrões que contribuem para a sua reprodução) quanto na econômica (quando se estabelece formas de exploração para a apropriação de capital). Entender essa análise dialética permite, sem restrições, desvendar e combater às opressões com a necessidade de uma articulação intrínseca dessas duas esferas, ou então, estará limitado a não resultar em mudanças concretas no caminho à emancipação dos sujeitos.

\footnotetext{
1 Atual nomenclatura utilizada para designar o segmento composto por Lésbicas, Gays, Bissexuais, Travestis e Transexuais.

2 Estudante de Bacharelado em Serviço Social do Instituto Federal de Educação, Ciência e Tecnologia do Ceará IFCE campus Iguatu.

3 Doutoranda em Educação na Universidade Estadual Paulista Júlio Mesquita Filho - UNESP e docente do Instituto Federal de Educação, Ciência e Tecnologia do Ceará - IFCE campus Iguatu.
} 
Nesse sentido, as opressões têm legitimação através do aparatoideológico de valores que hierarquizam os sujeitos, assim, é por intermédio da educação que se alcança a garantia do consenso, visto que passa a ser "internalizado" nos sujeitos os valores que contribuem para o desenvolvimento do capital, por isso que essa esfera é uma ferramenta indispensável para a manutenção do capitalismo e, como consequência, de disputas ideológicas de projetos políticos. Dentro das opressões que são invisibilizadas na escola, destacaremos o segmento LGBT com o intuito de contribuir para a disputa nesse espaço com a finalidade de obter um reconhecimento desse público, já que é imprescindível a busca por uma educação que viabilize a emancipação dos sujeitos. Dessa forma, entender que os sujeitos estão aprisionados a valores que usurpam a possibilidade de exercer suas subjetividades é iniciar um enfrentamento aos padrões de reprodução social da heteronormatividade, sexismo e binarismo que são impostos, entendendo os desafios para a implementação dessa proposta que não comunga com os interesses do capital e lança possibilidades de uma nova ordem societária. Assim, o presente artigo é fruto da investigação bibliográfica por meio do trabalho de estudos e análises de noticiários, artigos, relatórios, livros, além da busca por subsídios em dados estatísticos para fundamentar concretamente a exposição do tema.

\section{Os enfrentamentos necessários para uma educação com compromisso no combate à opressão LGBT}

Não podemos analisar a educação como um campo unívoco de decisões políticas, no caso, instrumentalizada apenas para o atendimento às demandas ditadas pelo capital, pois é possível identificar a existência da massa popular que exige reconhecimento na formação de profissionais e sujeitos que atendam as expectativas de construtores de uma sociedade livre dos valores que comungam com os princípios da ordem burguesa. Dessa forma, provam que é nesses espaços de conflitos que se percebe a contraconsciência (MÉSZÁROS, 2005, p. 121).

Dentre essas camadas populares estão as denominadas minorias sexuais e de gênero, as quais lutam, desde a década de 1970, pelo reconhecimento de suas questões específicas nos currículos das instituições escolares, e assim permitem ampliar o diálogo para as diversas manifestações das sexualidades e orientações e põem risco a consolidação das alas conservadoras. Um exemplo disso está explícito na proposta do currículo "multiculturalista", em que nega a reprodução social hegemônica de legitimar a supremacia do cânon branco, masculino, europeu, heterossexual. Assim, "o multiculturalismo mostra que o gradiente da desigualdade em matéria de educação e currículo é função de outras dinâmicas, como as de gênero, raça e sexualidade, por exemplo, que não podem ser reduzidas à dinâmica de classe.” (SILVA, 2003, p. 90).

Dessa forma, enxerga-se a necessidade de entender que, também dentro da educação, as demandas desses setores oprimidos estão intimamente confrontadas à lógica atual que rege as relações sociais, políticas e econômicas do modo de produção capitalista. Só nessa articulação se conseguirá aprofundar o debate e combater o cerne de toda e qualquer opressão que assola a sociedade, caso o contrário, limitar-se-á apenas no enfrentamento da manifestação da opressão e não na construção de valores lídimos com a superação dessa sociedade que hierarquiza as diferenças. 
Isso não é contraditório com as lutas ditas "específicas". Primeiro, porque dentro da "ordem metabólica do capital" as expressões culturais não se dão nem se encontram dissociadas de seu metabolismo, mas dentro de sua ideologia e de sua reprodução com fins voltados a assegurar os interesses da burguesia (claro, via exploração da classe trabalhadora); segundo, porque lutar pela extinção das desigualdades, opressões e exploração, enfim, lutar por emancipação plena, liberdade, exige a defesa de valores libertários - que não cedem espaço para a existência de preconceitos, discriminações, subordinações - antes, garantem aos sujeitos sociais o direito da livre expressão de suas subjetividades. (CISNE, 2005, p. 03).

Dentro dessa sociedade, a escola se torna imprescindível para estabelecer o consenso das massas com a construção de valores que são internalizados nos sujeitos. Portanto, a medida de inserir políticas de inclusão LGBT dentro da escola poderá tanto alcançar um lastro efetivo e concreto de reconhecimento desse público, colocando-se em antagonismo os atuais valores que são impostos, como também formará construção de novos valores que induzirão a práticas emancipatórias.

A partir daí, enfoca-se medidas em que a reprodução social esteja em colisão com as imposições que favoreçam a inabalável lógica do capital, mostrando que o sistema não adota somente a coerção, mas também o consenso. É assim que se exige uma tarefa ineliminável para a superação da opressão na escala conjuntural: a articulação entre a opressão por orientação sexual e identidade de gênero com a opressão econômica de classe, uma vez que é esta que vai determinar sua posição (oprimido/opressor) e suas limitações dentro da sociedade, em outras palavras, a inclusão de políticas LGBT na escola deverá contemplar o acompanhamento de medidas de enfrentamento à dinâmica do capital, caso seja a emancipação humana seu objetivo final.

É certo que o gênero não possui apenas sexo, mas possuiu classe, raça, etnia, orientação sexual, idade, etc. Essas diferenças e especificidades devem ser percebidas. No entanto, dentro desta sociedade, não podem ser vistas isoladas de suas macrodeterminações, pois, por mais que "o gênero una as mulheres", a homossexualidade una gays e lésbicas, a geração una as(os) idosas(os) ou jovens, etc., a classe irá dividi-las(os) dentro da ordem do capital. (CISNE, 2005, p. 03).

Logo após, Cisne (2005, p. 03) irá explicar melhor o que significa essa divisão dentro da sociedade marcada pelo conflito de classes e propõe uma intervenção política para esse enfrentamento:

A classe é pois, quem determina como essas mais variadas expressões de opressões irão ser vivenciadas por esses sujeitos. Assim, é que uma mulher da classe dominante explora uma mulher da classe trabalhadora, uma idosa pode explorar outra idosa, uma negra pode explorar outra negra. Os movimentos sociais devem, portanto, ter como cerne a luta de classes.

Com isso, para alcançarmos uma educação que vise a emancipação dos sujeitos será necessário o diálogo crucial entre a opressão por orientação sexual com a opressão central de classe, estabelecendo o horizonte de uma sociedade que contemple todas as subjetividades, assim estará questionando a manutenção da lógica ditada pelo capital. Se não for estabelecida essa articulação, essa reforma, como qualquer outra, poderá ser considerada, segundo Mészáros (2005, p. 109), uma contradição em termos, uma vez que servirá apenas como catalisador dos resíduos oriundos da natureza do desenvolvimento desse modo de produção. 
Portanto, para reforçarmos a necessidade de inserir o debate do público LGBT na educação, será necessário enfatizar medidas tanto para que haja um tratamento equânime dentro do ambiente escolar como uma possibilidade de enfrentamento aos padrões heteronormativos, sexistas e binários para que leve a uma possível libertação dos sujeitos que estão encarcerados a essa construção.

\section{O questionável papel da escola atual: a busca pela visibilidade LGBT dentro da educação}

Destarte, é visível a necessidade em abordar a homossexualidade no debate da educação, uma vez que nas políticas de inclusão dos espaços educacionais chegam a mencionar a necessidade de inclusão das mulheres, mas no que se refere ao combate à homofobia e da abordagem da homossexualidade não se tem a mesma preocupação. Isso é fruto de um descaso maior, já que não é mera coincidência até hoje o impedimento do termo "orientação sexual" no inciso IV do artigo $3^{\circ}$ que versa sobre a proibição da discriminação por pessoas de determinada "origem, cor, raça, sexo e idade" na Constituição Federal do Brasil de 1988.

Tal impedimento nos leva a por um paralelo com o racismo para analisar a importância da visibilidade e da informação sobre a homossexualidade nas escolas, partindo de um comparativo também com o abandono por parte do Estado. Para Miskolci (2005, p. 20), se percebermos, a maioria das pessoas se dizem não-racistas, apesar de constatarmos a grande diferença de raça entre brancos e negros. No caso da homossexualidade isso se torna mais agravante, as pessoas nem sequer temem ao dizer termos que incitam a violência a gays e lésbicas em uma justificativa de "liberdade de expressão". Diante disso, percebemos a ofensa a que este público está suscetível com a negação da proteção do Estado, e como isso na incidência que rebaterá no trabalho desenvolvido pela escola, reforçando a rejeição das práticas sexuais alternativas e na condução das hegemônicas nos níveis primários da fase humana.

Pode ser que a escola, aparentemente, tenha um posicionamento "neutro", mas toda essa falácia cai por terra quando ocultam a existência de diferenciadas práticas afetivas que podem cumprir um papel que arrisque a manutenção das formas tradicionais de relacionamento. Com isso, está aí o papel legitimador da reprodução da heterossexualidade compulsória disfarçada. O teórico queer brasileiro, Miskolci (2005, p. 19) explica:

A prática educativa fincada na suposta invisibilidade da sexualidade e no silêncio
sobre as formas diferentes de amar é homofóbica, pois pressupõe que ignorar
a existência de práticas sexuais entre pessoas do mesmo sexo levaria os jovens
a optarem pela heterossexualidade. Assim, a instituição escolar revela que sua
neutralidade em termos sexuais nunca passou de cumplicidade com a forma
de sexualidade hegemônica e prescrita como única. A neutralidade se funda no
objetivo de assumir uma só via para todos, ou seja, a neutralidade não passa de
heterossexualidade compulsória disfarçada.

Outro fator que o silenciamento dessa instituição fortalece é na falta de informação sobre as concepções de gênero, sexo e orientação sexual, o que acaba gerando uma aproximação de um sensocomum que subjuga essas categorias a uma lógica biológica e "natural". Em outras palavras, essas categorias se relacionam de forma unívoca, exemplo: o homem (sexo) permite naturalmente que se 
tenha comportamentos masculinos (gênero) e que seu desejo esteja direcionado para o sexo oposto (orientação sexual). Não se pode desviar desse caminho. Além disso, o mesmo silenciamento serve de subsídio para invisibilizar os sujeitos que destoam as práticas afetivas tradicionais. Essa rejeição serve como garantia da norma, de um "exemplo" para os demais do que pode vir a acontecer caso adotem ou compartilhem aquele comportamento transgressor.

O processo de ocultamento de determinados sujeitos pode ser flagrantemente ilustrado pelo silenciamento da escola em relação aos/às homossexuais. No entanto, a pretensa invisibilidade dos/as homossexuais no espaço institucional pode se constituir, contraditoriamente, numa das mais terríveis evidências da implicação da escola no processo de construção das diferenças. De certa forma, o silenciamento parece ter por fim "eliminar" esses sujeitos, ou, pelo menos, evitar que os alunos e as alunas "normais" os/as conheçam e possam desejá-los/as. A negação e a ausência aparecem, nesse caso, como uma espécie da garantia da “norma". (LOURO apud DINIS, 2008, p. 483).

Se o isolamento e a rejeição foram as medidas encontradas pela escola e pelo/a educador/a para mostrar como esse comportamento "perigoso" deve ser tratado na sala, agora, passa a ser a vez dos/ as próprios/as educandos/as mostrarem que aprenderam. Portanto, os/as aprendizes reproduzirão as práticas peculiares que variarão do xingamento à violência física e amizades clandestinas. Assim, a mesma escola que cultuava silenciosamente os padrões heteronormativos passa a assumir um posicionamento claro de opressor ao discriminar aquele/a que foi vítima do seu silêncio e, por conseguinte, essas consequências farão do oprimido o opressor de si mesmo. Assim, "diante dos xingamentos que menosprezam seus sentimentos aprenderão a se defender sendo cruéis consigo próprios, ou seja, deixando de expressar o que sentem e, provavelmente, lutando contra seus desejos." (MISKOLCI, 2005, p. 19).

A discriminação dentro da escola se difere das demais quando o próprio sujeito não consegue denunciar os acusados, uma vez que afirmar a sua orientação sexual pode gerar mais conflitos tanto no âmbito escolar quanto no familiar. Em linhas gerais, afirmar ser aquilo que seus colegas dizem é ainda mais constrangedor para si e agravante para a sua inferiorização. Os dados do FIPE (Fundação Instituto de Pesquisas Econômicas) de 500 escolas públicas brasileiras afirmam que os/as alunos/as comprovam o que discorremos anteriormente: dos/as entrevistados/ as 26,6\% assumem a afirmação "Eu não aceito a homossexualidade", 25,2\% de que "pessoas homossexuais não são confiáveis". "A homossexualidade é uma doença” tem a adesão de 23,2\% dos/as estudantes e, por último, "os alunos homossexuais não são normais” tem a porcentagem de 21,1\% (GUINOZA apud OLIVEIRA JR; MAIO, 2012, p. 04).

No que se refere aos/às docentes, esse percentual, da mesma pesquisa, aumenta significativamente, pela falta de intimidação ao por livre sua opressão constatando-se que $59,7 \%$ dos/as professores/as afirmam ser inadmissível a relação homossexual. Diante disso, estamos à frente de um novo desafio: a importância de conscientizar esse/a profissional que, da mesma forma que é utilizado/a para desenvolver uma prática opressora, pode desenvolver uma prática libertadora, ou seja, construir uma educação para a construção de valores libertários, caso esteja disposto/a a romper com as amarras da heteronormatividade. É 
importante ressaltar que se não há a contribuição dos/as professores/as tampouco poderemos avançar. É sobre isso que me deterei a seguir.

\section{O papel pedagógico para a emancipação da sexualidade: o/a professor/a como ferramenta da contramaré hegemônica.}

Entender que o/a professor/a terá um papel crucial para o processo de emancipação dele/a próprio/a e dos demais sujeitos que desde infância são "enquadrados" a uma lógica binária (hetero/homo, homem/mulher, feminino/masculino) é perceber que quem está dentro dessa instituição está passível a essa opressão, não importa a função que desempenha. Um exemplo disso é o comum posicionamento que se enxerga nos/as educadores/as ao adotarem que dentro da sala de aula todos/as eles/as não têm sexualidade. Isso é uma das formas de manter a opressão dentro do âmbito educacional, pois a sexualidade não deve ser comparada a um adereço, roupa ou bijuteria que se pode despir antes de entrar nos espaços que ocupam. Ela está inserida em todos/as em qualquer dos espaços que presenciem, é impossível desprendê-la. Assim, qualquer castração consigo com o intuito frustrado de um posicionamento "neutro" deve ser considerado como opressão a si mesmo/a.

Pressupõe-se, por exemplo, que a sexualidade é um assunto privado ou, ao menos, restrito ao lado de fora da escola. Na verdade, a sexualidade está na escola porque faz parte dos sujeitos o tempo todo e não tem como ser alocada no espaço ou em algum período de tempo. Ninguém se despe da sexualidade ou a deixa em casa como um acessório do qual pode se despojar. Na escola também se infere que todos se interessam ou se interessarão por pessoas do sexo oposto e que suas práticas sexuais seguirão um padrão reprodutivo. (MISKOLCI, 2005, p. 17).

Dessa forma, discorremos que não se deve encarar as políticas de inclusão do público LGBT como algo que favorecerá apenas a essas camadas que põem em questionamento a manutenção do sexismo e da heterossexualidade, mas que poderá ser um caminho para uma mudança no perfil do/a educador/a como forma de desprendimento dos preconceitos advindos de uma lógica macroscópica e histórica. Para isso, será necessário o envolvimento dos/as profissionais na temática se distanciando de um tratamento apenas restrito ao âmbito da ampliação da tolerância, que cai no reforço do que chamamos de "naturalização" da homossexualidade, e exige que todos/as protagonizem as mudanças radicais dentro desse espaço para que, no final, todos/as comunguem dos mesmos privilégios. Sobre a naturalização das orientações sexuais, Dinis (2008, p. 485) explicita:

Mas um dos riscos desta naturalização das orientações sexuais é que a relação com a diferença fique apenas no plano das políticas de tolerância, um respeito aos direitos do outro desde que o outro permaneça no seu eterno lugar de si mesmo, mantendo seguro os territórios delimitados de formas padronizadas de viver as condutas sexuais. Ou, então, apenas afrouxando os limites da tolerância para a inclusão de alguns dos/das desviantes mais bem comportados/as e que possam ser mais facilmente incluídos/as na ordem, criando novas zonas de exclusão para as/os que desafiam ainda mais as fronteiras de gênero, tais como indivíduos bissexuais, transexuais e outras experimentações de transgêneros.

Tal natureza é característica da pedagogia queer: ultrapassar as fronteiras da naturalização e da estabilidade da sexualidade e alcançar o orbital da construção social e histórica. Assim, prova que 
a tolerância não dá conta do objetivo proposto para a emancipação, já que os sujeitos permanecem intactos a sua condição de "normalidade". Dessa seguinte maneira, podemos reforçar:

Especificamente em relação à homossexualidade, a pedagogia queer não quer simplesmente estimular uma atitude de respeito ou tolerância à identidade homossexual. Ela tampouco quer estimular uma abordagem terapêutica, na qual a ênfase estaria no tratamento individual do preconceito e da discriminação. A abordagem baseada nas noções de tolerância do respeito deixa intocadas as categorias pelas quais a homossexualidade tem sido definida, histórica e socialmente, como forma anormal de sexualidade: ela apenas produz uma outra espécie de binarismo ao admitir, como diz Deborah Britzman, as categorias do heterossexual tolerante e do homossexual tolerado. Da mesma forma, a abordagem terapêutica transfere para o nível individual e psicológico uma questão que pertence ao nível institucional, social, cultural, histórico. (SILVA, 2009, p. 108).

Em suma, a ideia de tolerância às diferenças pouco contribui para a reflexão das opressões, uma vez que reforça a estática posição de um favorecimento ao culto do padrão transcendente de uma cultura superior sobre a "diferente" que é tomada como inferior. Na linha de raciocínio, a abordagem constituída pelos elementos de "tolerância", "respeito" e "convivência pacífica" camufla seu objetivo real de manter inviolável o patamar do valor próprio do padrão cultural hegemônico. Daí se enquadra um suposto combate às simetrias ao superficialmente limitar o enfoque ao convívio que, consequentemente, nutre os postos a dominação do/a "não-diferente" sobre o/a "diferente".

(...) essas noções deixam intactas as relações de poder que estão na base de produção da diferença. Apesar de seu impulso aparentemente generoso, a ideia de tolerância, por exemplo, implica também uma certa superioridade por parte de quem mostra a "tolerância". Por outro lado, a noção de "respeito" implica um certo essencialismo cultural, pelo qual as diferenças culturais são vistas como fixas, como já definitivamente estabelecidas, restando apenas "respeitálas". Do ponto de vista mais crítico, as diferenças estão sendo constantemente produzidas e reproduzidas através de relações de poder. As diferenças não devem ser simplesmente respeitadas ou toleradas. Na medida em que elas estão sendo constantemente feitas e refeitas, o que se deve focalizar são precisamente as relações de poder que presidem sua produção. (SILVA, 2009, p. 88).

Quanto ao protagonismo desses/as profissionais, percebe-se o efeito dialético do processo com que as benesses serão partilhadas: ao/à profissional será uma mudança para um perfil instigante no que se refere à cristalização das orientações sexuais nesse contexto, aos/às demais estudantes terão diante de si a possibilidade de si enxergar com aquele/a que transgride as normas do padrão social, Dinis (2008, p. 483 - 484) explica:

Nesse sentido, é provável que o/a educador/a será confrontado/a com a própria sexualidade. Assim, parece que a dificuldade da/do docente em tematizar a diversidade sexual também possa ser uma dificuldade em lidar com a sua própria sexualidade e com as múltiplas possibilidades de obter prazer. Ou seja, pensar a questão da homossexualidade pode ser um convite para que o/a educador/a possa olhar para sua própria sexualidade e pensar a construção histórico-cultural de conceitos como heterossexualidade, homossexualidade, questionando a heteronormatividade que toma como norma universal a sexualidade branca, de classe média e heterossexual.

Em decorrência disso, o/a educador/a passará a ter uma visão translúcida do véu do silêncio que veste a homofobia, no qual é o real posicionamento da escola diante da diversidade sexual, pois ele/a 
será vítima dos argumentos opressores que exigirá a retomada do posicionamento conservador da escola. Terá a frente outros desafios que estarão travados, agora de mudança no espaço de trabalho entre os/as gestores/as.

(...) a mera menção da homossexualidade vá encorajar práticas homossexuais e vá fazer com que os/as jovens se juntem às comunidades gays e lésbicas. A idéia é que as informações e as pessoas que as transmitem agem com a finalidade de "recrutar" jovens inocentes (...). Também faz parte desse complexo mito a ansiedade de que qualquer pessoa que ofereça representações gays e lésbicas em termos simpáticos será provavelmente acusada ou de ser gay ou de promover uma sexualidade fora-da-lei. Em ambos os casos, o conhecimento e as pessoas são considerados perigosos, predatórios e contagiosos. (BRITZMAN apud DINIS, 2008, p. 483).

Será o/a educador/a o/a agente que poderá fazer com que aquele exemplo de sala isolado e encarado como ignóbil seja o estopim para as mudanças por um espaço sem opressões, nas particularidades que não estejam engessadas em uma lógica excepcionalmente reprodutiva das relações afetivas, explicitando também como a regra geral das relações, ditadas pelo capitalismo, se apropria dessa diferença para sua manutenção. Ele/a deve encarar no que é pontual e preciso uma das formas de levar o debate da emancipação para uma sala, uma escola e uma comunidade. Assim,

a particularidade é compreendida, pois, como uma "categoria ontológica reflexiva que permite que as leis sociais tendenciais se mostrem aos sujeitos envolvidos na ação [...] e ganhem um sentido analítico-operacional nas suas vidas singulares". É onde a "legalidade universal se singulariza e a imediaticidade do singular se universaliza.” (PONTES apud CISNE, 2005, p. 06).

Mas ainda sabemos que existem poucas políticas afirmativas das minorias para a educação. Então, se lançam dúvidas sobre a possibilidade de se efetivar esse vislumbramento. Por isso, reconfigurase o papel dos sujeitos que se propõem a encarar os desafios opressores da escola.

\section{A ausência de políticas de inclusão LGBT na esfera educacional e os rebatimentos para a sala de aula}

No país houve uma grande resistência por setores ligados à religião para que a sexualidade não tenha espaço nos currículos escolares, mas constata-se que, desde 1920, é lei a abordagem ao tema na instituição. Hoje, não é diferente, as camadas eclesiais, juntamente com outros setores políticos, são os que buscam impedir a construção de novos valores que contradizem a legitimidade dos padrões atuais. Além disso, os/as professores/as são despreparados/as ou, muitas vezes, policiados/ as a restringir a sexualidade ao natural, já que precisam ser disciplinados e vigiados, pois esses temas podem ser ameaçadores e perigosos (JUNQUEIRA apud OLIVEIRA JR; MAIO, 2002, p. 01).

Outro problema é que muitas escolas comungam da intervenção religiosa, assim não assumem o aprofundamento da temática da sexualidade para o âmbito de uma construção histórico-social e ficam apenas na prevenção de doenças sexualmente transmissíveis (DST's) e da gravidez que, por sinal, ao sempre estar vinculado à dimensão biológica, pode reforçar preceitos que desfavorecem práticas sexuais LGBT e às mulheres. 
Em suma, a abordagem da sexualidade pela via da prevenção de doenças sexualmente transmissíveis (DST's) cai facilmente em um discurso conservador quer sobre práticas sexuais hegemônicas quer sobre aquelas socialmente ainda mal compreendidas. $\mathrm{O}$ ideal é abordar a sexualidade como algo mais amplo e menos restrito a uma abordagem de saúde pública. (MISKOLCI, 2005, p. 23).

No Brasil, o programa Brasil Sem Homofobia, fundado no ano de 2004, tem no seu artigo $5^{\circ}$, intitulado Direito à Educação: promovendo valores de respeito à paz e à não discriminação por orientação sexual, a defesa em "Estimular a produção de materiais educativos (filmes, vídeos e publicações) sobre orientação sexual e superação da homofobia" (BRASIL, 2004, p. 22).

Em 2011, foi impedida a divulgação do kit anti-homofobia nas escolas públicas. O kit contava com 06 boletins, 01 caderno, recursos audiovisuais e 03 vídeos. Caso fosse aprovado, teria o lastro de inserção em seis mil escolas públicas de ensino médio no país. Mas essa ferramenta da política de inclusão não conseguiu ser implantada, em decorrência da expressividade que a bancada religiosa ocupa no parlamento. Isso é prova que ainda há grandes impedimentos na luta por direitos em meio a um Estado que sofre sérios riscos de escamotear sua laicização.

Diante disso, percebendo a dificuldade do Estado em reconhecer o público LGBT, não se deve abandonar a esfera educacional como um caminho para a contribuição da superação da opressão de gênero e orientação sexual, já que, conforme a pesquisa Diversidade sexual e homofobia no Brasil - Intolerância e respeito às diferenças sexuais (2009), indica que a escolaridade pode contribuir de monta para a diminuição da prática homofóbica ao constatar que $52 \%$ dos brasileiros que nunca frequentaram a escola apresentam comportamentos homofóbicos, em contrapartida com 10\% dos pesquisados que têm Ensino Superior manifestam essa prática. Portanto, enquanto esse público se torna vítima do descaso do Estado em não ser reconhecido na esfera estatal com políticas inclusivas de caráter universal, os/as educadores/as e profissionais em geral terão que, a princípio imediato, adotar medidas estratégicas para implementar no cotidiano práticas que tenham como finalidade o horizonte da emancipação, mesmo diante de todas limitações que são impostas. Isso não quer dizer que essas práticas serão o objetivo último, mas que o cotidiano deve ser encarado para além de um espaço da alienação, mas também de reflexão dos sujeitos.

Um exemplo dessas ações pode ser a busca por medidas do reconhecimento de datas comemorativas das camadas subalternas dentro do calendário escolar. Assim se poderá estabelecer uma conexão para promover o debate na escola com informação, aproximação com os temas e exposição da agenda de luta do setor oprimido em foco. Então, para que sejam comemoradas conjuntamente com o Dia do Trabalhador (01 de Maio), o do Índio (19 de Abril) e o da Consciência Negra (20 de Novembro) as seguintes datas: Dia da Visibilidade Trans (29 de Janeiro), Dia Internacional da Pessoa com Deficiência (03 de Dezembro), Dia Mundial do Orgulho LGBT (28 de Junho), Dia Nacional do Idoso (01 de Outubro), Dia Nacional da Visibilidade Lésbica (29 de Agosto), entre outras.

Dando continuidade, será também importante que se estabeleça uma abordagem que dinamize e proponha uma superação da binaridade com a criação de formas alternativas de relações com o outro, para que não se tenha que encaixar em um dos dois lados. 
Dessa forma, um novo exercício pedagógico é um convite a reinventarmos nossas relações com os outros e com nós mesmos, nos desprendermos de nós mesmos, liberar a vida aí onde ela está aprisionada, devir-outro, tornarmos outra coisa. A produção permanente de formas subjetivas que desconstruam as estruturas binárias e excludentes do tipo adulto-criança, homem-mulher, heterossexual-homossexual, outro-eu mesmo. Uma resistência à tentativa de capturar as diferenças como signo de uma identidade, já que a essência da alteridade é justamente um tornar-se. Pois um dos riscos, mesmo quando os documentos que tematizam as exclusões de gênero passarem a incluir temas como a homossexualidade ou as diferenças sexuais, é que persistamos com lógicas binaristas, nas quais a inclusão de um termo sirva sempre como automática exclusão do outro. (DINIS, 2008, p. 489).

Por fim, propomos expor a opressão por orientação sexual nos diversos contextos pondo a transversalidade na história, na sociologia e na opressão econômica de classe para que não se analise de forma engessada e isolada no tempo e no espaço, podendo abrir para análise de outras categorias relacionadas. Além disso, não se pode deixar de esquecer que a abordagem comum da homossexualidade e das diversas expressões na escola terá que transpor os limites do entendimento superficial da tolerância, de respeito ao outro, e alcançar o orbital de se refletir a partir do outro com os questionamentos de construção de diversas subjetividades na busca por sujeitos que construam suas próprias singularidades.

Ao colocar em discussão as formas como o 'outro' é constituído, levariam a questionar as estreitas relações do eu com o outro. A diferença deixaria de estar lá fora, do outro lado, alheia ao sujeito, e seria compreendida como indispensável para a existência do próprio sujeito: ela estaria dentro, integrando e constituindo o eu. A diferença deixaria de estar ausente para estar presente: fazendo sentido, assombrando e desestabilizando o sujeito. Ao se dirigir para os processos que produzem as diferenças, o currículo passaria a exigir que se prestasse atenção ao jogo político aí implicado: em vez de meramente contemplar uma sociedade plural, seria imprescindível dar-se conta das disputas, dos conflitos e das negociações constitutivos das posições que os sujeitos ocupam. (LOURO, 2001, p. 550)

Para que um dia, ainda que longínquo a hoje, estejamos livres para criarmos as subjetividades que traduziram nosso próprio eu e que toda essa discussão soe como algo de um tempo remoto, como diz Dinis (2008, p. 490) citando Costa.

Neste dia, veremos nossas crenças presentes como vemos as crenças em feitiçaria, ou seja, como produtos obtusos e obsoletos da imaginação; como "um erro do tempo". Os indivíduos, nesta cidade ideal da ética humanitária e democrática, serão livres para amar sexualmente de tantas formas quantas lhes seja possível inventar. O único limite para a imaginação amorosa será o respeito pela integridade física e moral do semelhante. "Heterossexuais, bissexuais e homossexuais" serão, então, figuras curiosas, nos museus de mentalidades antigas. Na vida, terão desaparecido como "rostos de areia no limite do mar" (COSTA apud DINIS, 2008, p.490).

\section{CONSIDERAÇÕES FINAIS}

Entendemos que o papel da escola nos atuais moldes é um forte mecanismo de consenso das massas populares na adequação aos ditames do capital. Dessa forma, utiliza-se da internalização dos valores para garantir um adestramento da classe trabalhadora. Porém, não devemos nos limitar a enxergar só essas barreiras para alcançarmos uma educação que vise a emancipação dos sujeitos. É necessário manter uma forte articulação entre os impedimentos políticos e econômicos 
que mantêm a atual sociedade e contemplar as singularidades dentro da totalidade em que os sujeitos estão inseridos.

O papel da escola, no que se refere à diversidade sexual, se reforça através da opressão do silêncio, do isolamento e da rejeição aos/às que transgridem os mecanismos dominantes da heteronormatividade. Não é difícil percebermos o avanço do conservadorismo e de um processo de ofensiva à laicização do Estado que repercute nas políticas de inclusão do público LGBT e na naturalização da homofobia, gerando cada vez mais o crescimento das mortes por intolerância sexual. Segundo o Relatório Anual 2013/2014, de Assassinatos de Homossexuais (LGBT) no Brasil, do Grupo Gay da Bahia (GGB), o país permanece ocupando o primeiro lugar em ocorrência de crimes homo-transfóbicos, onde se concentra $40 \%$ dos assassinatos a travestis e transexuais no mundo. Além de ser também constatado um assassinato LGBT a cada 28 horas, vale ressaltar que muitos desses assassinatos são caracterizados tipicamente como os "crimes de ódio" em que prevalece a tortura.

Um dos primeiros passos para se alcançar mudanças, mesmo que de forma esporádicas, é a politização do/a educador/a no papel acerca do gênero e da sexualidade para que não se produza o caminho restrito da sexualidade (sexo, gênero e orientação sexual), entendendo também como uma vítima desse processo de reprodução social. Além disso, a temática consegue ser uma possibilidade de mudança do perfil do/a educador/a. Ao reavaliar os conceitos que são naturalizados, também esse sujeito enfrentará novos desafios no âmbito da gestão escolar.

Outra consideração que pontuei e posso destacar é a ausência da defesa de um debate dentro das minorias, no que se refere à diversidade sexual, ocupando, assim, uma posição secundarizada nas opressões. Além de reforçar a defesa do empoderamento do professor/a no debate da sexualidade dentro da sala de aula, uma vez que existem escolas de tendência religiosa que quando se propõe a debater sexualidade, restringem-se ao mero biológico, o que resulta em um enfrentamento de saúde preventiva, esquecendo a visão histórico-social, impedindo tanto a liberdade do professor/a quanto o processo de um conhecimento amplo e fundamentado.

Por mais que ainda não se tenha alcançado o patamar necessário de implementação de políticas que trazem reformas de âmbito universal, os/as educadores/as devem encontrar medidas, mesmo dentro dos limites impostos, para por um mínimo de questionamento nos espaços educacionais que ocupam através de estratégias de enfrentamento à alienação posta pela óptica heteronormativa e sexista, já que não se deve abandonar a esfera educacional como ferramenta que contribui para a emancipação humana. Para isso, exemplifiquei a inserção de datas comemorativas do público oprimido no calendário escolar, assim, mesmo que pontualmente, terão a possibilidade de ser o alvo de discussões dentro de um espaço que se firmava silenciosamente a opressão desses sujeitos. 


\section{Referências}

BRASIL. Ministério da Saúde. Brasil sem Homofobia: Programa de combate à violência e à discriminação contra GLTB e promoção da cidadania homossexual. Brasília, DF, 2004.

CISNE, M. Marxismo: uma teoria indispensável à luta feminista. In: $4^{\mathrm{o}}$ Colóquio Marx e Engels, 2005, Campinas- SP. Disponível em:http://www.unicamp.br/cemarx/ANAIS\%20IV\%20 COLOQUIO/comunica\%E7\%F5es/GT4/gt4m3c6.PDF. Acesso em: 08 abr. 2013.

DINIS, N. F. Educação, relações de gênero e diversidade sexual. Educ. Soc., Campinas, vol. 29, n. 103, p. 477-492, maio/ago. 2008

EDUCAR para conviver. JORNAL CARTA CAPITAL, São Paulo, 8 março 2013, Disponível em: www.cartacapital.com.br/carta-fundamental/educar-para-conviver.' Acesso em: 10 abr. 2013.

GGB - Grupo Gay da Bahia. Relatório Anual de Assassinato de Homossexuais no Brasil (LGBT) relativo a 2013. Disponível em: http://www.midianews.com.br//storage/webdisco/2014/02/14/ outros/747486191270d149b81fdfe548b921d1.pdf. Acessado em 20 de jun. 2014.

LOURO, G. L. Teoria queer - Uma política pós-identitária para a Educação. Estudos Feministas: segundo semestre de 2001, p. 541 - 553. Disponível em: http://www.scielo.br/pdf/ref/v9n2/8639. pdf. Acesso em: 08 abr. 2013.

MÉSÁROS, I. A Educação para além do Capital. São Paulo: Boitempo, 2005.

MISKOLCI, R. Um corpo estranho na sala de aula In: ABRAMOWICZ, Anete e SILVÉRIO, Valter Roberto. (Editores) Afirmando Diferenças. Campinas, Papirus, 2005, p. 13-25.

OLIVEIRA JR, I. Batista de; MAIO, E. Rose. Cartilha da discórdia: Recortes acerca do Kit AntiHomofobia do MEC. In: Seminário de Pesquisa do PPE, 2012. Maringá. Disponível em: www.ppe. uem.br/publicacoes/seminario_ppe 2012/.../co.../062.pdff. Acesso em: 08 de abr. 2013.

SILVA, T. Tadeu da. Documentos de identidade: uma introdução às teorias do currículo. Belo Horizonte: Autêntica, 2009. 